\title{
Discussion on Talent Cultivation of Architectural Innovation and Entrepreneurship in Private Colleges and Universities
}

\author{
Guan Wenjuan \\ College of Wuhan University of Science and Technology, Wuhan, Hubei, China, 430083
}

Keywords: private; architecture major; innovation and entrepreneurship; talent cultivation

\begin{abstract}
Starting from the importance of the talent cultivation of innovation and entrepreneurship of architecture major in private colleges and universities, this paper summarizes the status quo of the model for innovation and entrepreneurship of architecture major in colleges and universities at home and abroad, and analyzes how to improve the innovation spirits, entrepreneurial awareness and abilities of innovation and entrepreneurship of students from architecture major in private colleges and universities under limited resources and conditions.
\end{abstract}

\section{Introduction}

With the rapid development of China's economy, architecture industry has experienced rapid development over the past few decades, and architectural design professionals and architecture practitioners have significantly increased. However, at the current stage of slowing economic growth and the contraction of real estate industry, the demand for architectural design talents has reduced, and the employment situation of architectural design students has become severe. The traditional theoretical teaching or theoretical indoctrination teaching model on the university campus has not adapted to the current industry environment. The cultivated ordinary college students have no advantage in such a highly competitive employment market and high demanding industry background. The report of the $18^{\text {th }}$ CPC National Congress proposed: "To guide workers in changing employment concepts, encourage multi-channel and multi-form employment and promote entrepreneurship to promote employment." Therefore, how to cultivate the architectural talents adapt to the current economic environment, how to enhance their innovative spirits, entrepreneurial awareness and abilities of innovation and entrepreneurship, and how to provide students with a relaxed and innovative entrepreneurial environment is the focus of the cultivation of university architecture professionals in a period of time in the future.

In May, 2015, the General Office of the State Council issued Implementing Opinions on Deepening Reforms in Innovation and Entrepreneurship Education in Colleges and Universities of the General Office of the State Council which puts forward a series of guiding opinions on how to deepen innovation and entrepreneurship education reform in colleges and universities from the general requirements, main tasks and measures and strengthening organizational leadership, which points out the directions for innovation and entrepreneurship promotion and reform in major colleges and universities throughout the country and is also the main guiding document for this paper. According to the Notice of the General Office of the Ministry of Education Concerning the Implementation of the National Innovation and Entrepreneurial Bases for Colleges and Universities (The Ministry of Education Hall Letter No. [2015] No. 18), 50 "National Innovation and Entrepreneurial Bases for Colleges and Universities" of the Ministry of Education were elected according to the recommendation of the related unites and the panel of experts, which has played a role as a model pilot for research across the country. However, of the 50 colleges and universities on the list, there are only 1 private college. How to promote the innovation and entrepreneurship education reform in private colleges and universities will be a very urgent research topic.

Private colleges and universities have a place in China's higher education system. However, compared with various public institutions, there are problems such as shortage of funds, limited teachers, inadequate laboratory construction, low social recognition, and lack of enthusiasm for 
innovation and entrepreneurship of students. Under the current trend of deepening reforms in innovation and entrepreneurship education in colleges and universities of China, the teaching reform of the innovation and entrepreneurship talent cultivation model for architecture major in private colleges and universities is urgently needed. How to improve students' innovative spirits, entrepreneurial awareness, and innovation and entrepreneurship abilities under limited resources and conditions is the focus of this study.

\section{Converse the Classroom Teaching Format}

For a long time, the cultivation of talents in architecture has mainly been through a combination of theoretical studies, design courses, and design practices. These teaching processes mainly inculcate students' knowledge, allow students to accumulate more knowledge points and evaluate students only based on how much knowledge is mastered. Students' potential and the ability to innovate are neglected during the course of time, which results in students' subjective initiative and creativity not being well demonstrated. If the classroom teaching format is conversed, the classroom will be handed over to students. The teacher will arrange the topic and design plan for students in advance. Students will collect the necessary information from the library, the Internet, MOOC and other related channels before class. Result sharing and discussion in the form of discussion groups will be done. Finally, the results of the discussions in each group are displayed in the class. Students can learn from each other, enhance communication, improve the subjective initiative of learning, and stimulate students' sense of innovation. Teachers just organize and coordinate.

\section{The Cultivation of Innovative Thinking}

Innovation is the foundation for the development of any discipline. Architecture is originally a discipline of design. The cultivation of its innovative thinking is particularly important. It can start from the following aspects.

\subsection{The cultivation of innovative thinking in space creation}

Art of architecture is the art of space. Real architects are the shapers of the space environment. For students majoring in architecture, how to create the ideal space and let the space performance have certain innovation is a question that needs to be considered all the time. At the same time, the expression and creation of space cannot only be limited to drawings, but also need to constantly refining and modifying through the use of more models and construction works, so that the space creation of design works can be more in line with the functional and aesthetic requirements.

\subsection{The cultivation of innovative thinking of program design ability}

Each design project has its own specific site conditions. Each designer has his or her own unique thinking mode. The teachers' modification of students' programs cannot be too much to add their own design concepts, resulting in the similarity of students' programs, and students should be encouraged to design distinctive programs and students are required to carefully scrutinize programs and make models to analyze the programs more intuitively.

\subsection{The cultivation of innovative thinking of discussions and exchanges}

In the creative process of the design program, teachers can divide students into several design groups. They should actively encourage discussions and exchanges among students, promote students' self-thinking and self-learning abilities, which has promoting effect of the formation of innovative thinking.

\subsection{The cultivation of innovative thinking in traditional ethnic culture}

The nation is the world, and Chinese classical architecture and classical gardens are the essence of China's culture for thousands of years. It is not arty to analyze, feel and appreciate the design 
essence and literary sentiments among students, but only to increase the accumulation and precipitation of culture. Under the background of the invasion of Western culture, many practitioners have gradually forgotten and neglected traditional ethnic culture, which is extremely sad. Teachers should encourage students to respect and study traditional national culture and find creative inspiration from them. From this, we can extract certain cultural symbols and interpret them with new materials, techniques and forms. Such a design work will stand the test of time.

\section{Strengthen the Practical Ability}

It is not enough for the graduates of architecture to have innovative thinking. The strengthening of practical ability is also very important.

\subsection{Strengthen the ability of site design practice}

In the teaching experience, some students attach great importance to the design of the building monolith, the functional relationship of the plane, the analysis of traffic flow, the modeling of the facade, and so on. But the relationship between architecture and the environment and the relationship between architecture and the city are not drawn enough attention, which is a serious misunderstanding. The building and the environment are completely detached, and the entire site is chaotic. In fact, the site design sometimes directly determines the conception and concept of architectural design. Good site design can make the building be unique and individual, not only relying on exaggerated shapes or brilliant colors to capture the eye.

\subsection{Strengthen green building and environmental protection practice}

Buildings are destructive to the environment. With the deteriorating living environment, people are beginning to think about how to destroy the environment less in the construction and use of buildings, and at the same time ensure the comfort of users. Green building was born and raised. Countries in the world have proposed and implemented green building evaluation standards according to their own national conditions. China has also updated green building standards that are more suitable for China's national conditions in 2015. This is the demand of the times, and it is also a requirement for our living environment. The Ministry of Construction requires that the new building must meet the 3-star Standard for Green Building, which is a brand-new reform in architecture industry. As the cradle for the architecture professionals, the green building standards and evaluation system should be included in the course so that students can meet the needs of the market faster after graduation.

\subsection{Strengthen social practice ability}

Teachers should inspire students to think about social issues and phenomena. Architecture has strong social attributes and is a history book of social development. Teachers can provide discussion and sharing platform about the hot issues of today's society for students and raise students' concerns about social issues. They can also explore how to solve or weaken these problems in architecture industry and inspire students to discover problems and solve problems, such as social aging issues, food safety, transformation of old cities and other hot social issues.

\subsection{Strengthen the ability of computer practice}

Computer-aided drafting has become a very important part of architectural design. It can help designers to express design ideas more conveniently and accurately, and count and calculate data. Commonly used computer software includes revit building for program design, Auto CAD for construction drawings, Tian Zheng, Sketchup for simple architectural performance drawings, 3Dmax for formal renderings and Photoshop, and software for green building are Ecotect for lighting simulation, Airpark for wind environment analysis, CadNa/A for sound environment analysis, PKPM for energy saving design, eQuest for Energy Analysis, etc.

The strong support of colleges and universities for the development of students' creative abilities is also very important, which can be done in the following aspects: 


\section{Encourage teachers to practice internships}

Many teachers directly go to colleges and universities for teaching work after graduation without experience in internships in enterprises. Therefore, the teaching will only be limited to the theory and cannot be vividly developed and applied, so students will also feel boring in class. Colleges and universities can organize teachers to work out in enterprises, learn the practical application capabilities of enterprises, and enhance understanding of practical projects. Teachers' practical ability and innovative ability are improved, and naturally they can promote students' practical ability and innovation ability.

\section{Introduce a joint cultivation model for school-enterprise cooperation}

The school system of architecture is generally five years. The last year is an internship for students when students will go to enterprises for internships and complete the graduation design at the same time. In fact, students really do not have much time for internships in enterprises. They also have to take into account both enterprises and colleges. Sometimes, graduation design and internships are not completed well. In the face of these problems, we can introduce a joint cultivation model for school-enterprise cooperation, streamlining the in-school curriculum within three years, and directly arranging the remaining two years for internship. On the one hand, students are exposed to actual cases earlier, which can improve their professional design level. On the other hand, the experience in enterprises is also very meaningful for the completion of graduation design in the later period. In addition, early contact with the society has a certain effect in enlarging students' visions and improving the ability of innovation.

\section{Encourage students to be cross-major innovative}

It has been learned that many students did not know about the majors they reported after their college entrance examinations, but they chose these majors only because of being curious or impulse. They did not find themselves interested in the majors they studied until they majored in professional courses. However, because some credits have already been completed and the majors have to be re-educated after re-professionalism, they just pushed themselves to finish all the courses. However, because they are not interested in this major, they would like to be engaged other fields after graduation. However, there is no other professional knowledge reserve, so it is also very difficult in employment, which is a great waste of time.

Colleges and universities can formulate a policy that students can transfer credits to other majors to encourage students who want to transfer majors or choose other interests. Allow students to choose the majors that they are really interested in, improve their learning initiative, and also cultivate their innovative spirits. Colleges and universities must also retain the student status and credits and encourage to make bold attempts for the students who already have some mature entrepreneurial ideas or already started a business.

\section{Cooperation of colleges and universities}

Due to the limitations of private colleges and universities' own conditions, such as shortage of funds, limited teachers, inadequate laboratory construction, low social recognition, and lack of enthusiasm for innovation and entrepreneurship among students, students' creative spirits, entrepreneurial awareness and innovation and entrepreneur abilities are greatly limited. Private and public colleges and universities can establish effective cooperation mechanisms. Students with innovative entrepreneurial spirits can be cultivated across colleges, and exchanges and studies of different colleges and universities can also promote the development of private colleges and universities. 


\section{Summary}

The cultivation of architectural innovation and entrepreneurship talents in private colleges and universities is a long-term construction process. Although it is more difficult, it is an important content that benefits the majority of students and the society. Private colleges and universities must combine their own characteristics and combine with the characteristics of students to develop a unique path for students' innovation and entrepreneurship cultivation.

\section{References}

[1] Ye Yanbing. Exploring the construction of an innovation and entrepreneurial practice platform for architecture professionals [J].

[2] Han Ying, Liang Xianchao. Practice of Innovative Training Program in Applied Architecture Specialty[J]. Advanced Architecture Education, 2011, 20 (4): 148-151

[3] Huang Wei, Tang You, Tong Mingliang. Research on the mode of innovation and entrepreneurship training in private colleges and universities based on regional economic development[J]. Journal of Heilongjiang August First Land Reclamation University, 2013, 25 (2): 92-94 